\title{
Xanthan production with the hydrolysate of wheat straw
}

\author{
Zhang Zhi-guo* \\ Collage of Chemistry and Chemical Engineering, University of the Chinese Academy of Sciences, \\ Beijing, China \\ * Corresponding author. zhangzhiguo@ucas.ac.cn
}

Keywords: Xanthan gum; Detoxification; Steam explosion; Wheat straw; Xanthomonas campestris Abstract. Hydrolysate of steam-exploded wheat straw (SEWS) was used as the carbon source of xanthan production. The effects of common inhibitors generated during steam explosion on xanthan production were evaluated; a combine method was used to improve the fermentability of enzymatic hydrolysate of SEWS. All the three groups of compounds (weak acid, furan derivatives and phenolic compounds) inhibited xanthan generation; furan derivatives and phenolic compounds could be reduced by using the combinations of low steam pressure and long maintain time; flocculation was effective to remove phenolic compounds; weak acid and furan derivatives could be removed when SEWS was air-dried. Using the detoxified hydrolysate of SEWS, the xanthan production attained $20.7 \mathrm{~g} \mathrm{~L}^{-1}$ and the yield was $0.62 \mathrm{~g}$ xanthan per g sugar (glucose and xylose). It was concluded that SEWS is a potential carbon source of xanthan fermentation.

\section{Introduction}

Xanthan gum, a microbial polysaccharide secreted by Xanthomonas bacteria, has a variety of industrial applications [1]. In general the gum is produced by fermentation and the most common carbon source is sucrose and starch [2]. To reduce the production cost, some scientists are trying to use some low-cost raw materials to produce xanthan [3].

Lignocelluloses are major source of renewable organic matter. Recently, scientists hope that sugar derived from lignocelluloses can be used as carbon source for industrial fermentation. Now, the most attention-grabbing product is cellulosic ethanol [4]. However, sugar concentration of lignocellulosic hydrolysate is much lower than that of industrial media in ethanol production. This is one of the key bottlenecks of cellulosic ethanol commercialization [5]. Compared with the ethanol, xanthan fermentation requires much lower sugar concentration. Commonly used sugar concentration in xanthan production in industry now is below $40 \mathrm{~g} \mathrm{~L}^{-1}$ [2]. The value is close to that of batch enzymatic hydrolysate of pretreated lignocellulosic material without removal of lignin [6]. Hence, xanthan production with lignocellulosic material might be a more pragmatic choice.

Prior to enzymatic hydrolysis of lignocellulose, some pretreatments are necessary to reduce the barrier to enzyme attack. In this study, steam explosion was used as apretreatment method, which has been proved to be a cheap and efficient technology [7]. However, some compounds derived from degradation of polysaccharide and lignin are generated during the pretreatment [8]. Hence, the sensitivity of xanthan gum producing strain to these compounds and detoxification is worth studying.The aim of this study is to prove the feasibility of xanthan production with detoxificated enzymatic hydrolysate of steam-exploded wheat straw (SEWS). 


\section{Materials and methods}

Microorganism Xanthomonas campestris CGMCC 1.1781, obtained from China general microbiological culture collection center, was used in this study. The bacteria were grown on potato dextrose agar slants at $30^{\circ} \mathrm{C}$ for 3 days.

Material Wheat straw harvested from local farmer in the suburb of Xinle, Hebei Province, China, air-dried and stored inside a dry and cool room for less than 4 months. SEWS was prepared according to reference [9]. Penicillium decumbens cellulase was provided by the Ningxia Cellulase Preparation Plant. Filter paper activity was determined to be $110.0 \mathrm{IU} \mathrm{ml}^{-1}$.

Enzymatic hydrolysis of SEWS Sixty grams SEWS, $11 \mathrm{ml}$ cellulase solution and $420 \mathrm{ml}$ tap water $(\mathrm{pH} 4.8)$ were blended in a 2-L flask. The mixture was incubated in a rotary shaker at $50{ }^{\circ} \mathrm{C}$ and $150 \mathrm{rpm}$ for $2 \mathrm{~d}$.

Evaluation of inhibitors effect on xantan production A salt solution (glucose $30, \mathrm{NH}_{4} \mathrm{NO}_{3} 1$, yeast extract powder $3, \mathrm{MgSO}_{4} \bullet 7 \mathrm{H}_{2} \mathrm{O} 0.25, \mathrm{Na}_{2} \mathrm{HPO}_{4} 0.1, \mathrm{CaCO}_{3} 3 \mathrm{~g} \mathrm{~L}^{-1}$ ) was used as moistening medium. The suspension of $X$. campestris with a concentration of about $4.8 \times 10^{8}$ cells per milliliter was used as inoculum. To evaluate the effects of inhibitors, desired amount of formic acid, acetic acid, furfural and vanillic aldehyde were add respectively. Cultivation was carried out at $30{ }^{\circ} \mathrm{C}$ and $220 \mathrm{rpm}$ on a rotatory shaker with $250-\mathrm{ml}$ conical flasks for $72 \mathrm{~h}$, in which $50 \mathrm{ml}$ media and $5 \mathrm{ml}$ inoculum was added.

Detoxification by flocculation SEWS was immerged in ten times weight of distilled water at $80{ }^{\circ} \mathrm{C}$ for $6 \mathrm{~h}$. Then the mixture was centrifuged to obtain extraction. To study the detoxification effect of flocculation, $\mathrm{CaO}$ and phosphate acid was added. The amount and sequence were arranged according to experimental need.

Fermentation with enzymatic SEWS hydrolysate The example was carried out with the same condition as above. The hydrolysate in which $\mathrm{NH}_{4} \mathrm{NO}_{3}\left(1 \mathrm{~g} \mathrm{~L}^{-1}\right)$, yeast extract powder $\left(3 \mathrm{~g} \mathrm{~L}^{-1}\right)$, $\mathrm{MgSO}_{4} \cdot 7 \mathrm{H}_{2} \mathrm{O}\left(0.25 \mathrm{~g} \mathrm{~L}^{-1}\right)$ and $\mathrm{CaCO}_{3}\left(3 \mathrm{~g} \mathrm{~L}^{-1}\right)$ were added was used as fermentation media.

Analytical methods Biomass concentration was estimated by dry cell weight method. The broth samples were diluted by a factor of 10 with distilled water after they were adjusted to $\mathrm{pH} 3$ with $\mathrm{HCl}\left(5 \mathrm{~mol} \mathrm{~L}^{-1}\right)$. Then diluted solutions were centrifuged at $14000 \times \mathrm{g}$ for $30 \mathrm{~min}$ at $5{ }^{\circ} \mathrm{C}$ to precipitate the cells. Xanthan gum concentration was determined by precipitating the entire broth with 2 volumes of $95 \%$ ethanol after $\mathrm{pH}$ was adjusted to 3 with $\mathrm{HCl}\left(5 \mathrm{~mol} \mathrm{~L}^{-1}\right)$. Glucose and xylose concentrations in broth were estimated by determining the concentration in supernatant liquor. The contents of inhibitors in SEWS were determined after they were extracted by distilled water. SEWS was mixed with ten times weight of distilled water, sealed and maintained at $80{ }^{\circ} \mathrm{C}$ for $6 \mathrm{~h}$. The concentration of formic acid, acetic acid, furfural, glucose and xylose were determined by HPLC (Agilent, US) with a refractive index detector (RID agilent, US) using an Aminex $\mathrm{HPX}-87 \mathrm{H}$ column (Bio-Rad) at $35{ }^{\circ} \mathrm{C}$ with $5 \mathrm{mmol} \mathrm{L}^{-1} \mathrm{H}_{2} \mathrm{SO}_{4}$ as the mobile phase at a flow rate of $0.6 \mathrm{ml} \mathrm{min}-1$. Analysis method of phenolic compounds was according to Standard Methods for the Examination of Water and Wastewater [10]. The values of acetate and pyruvate contents of xanthan molecular were measured by HPLC method reported by Cheetham [11]. 


\section{Results and Discussion}
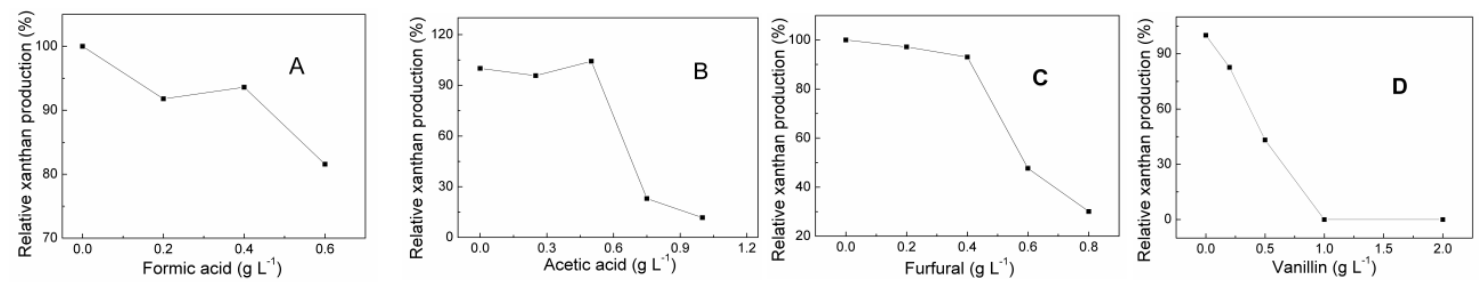

Figur 1 Relative level of xanthan productivity during the fermentation of Xanthomonas campestris CGMCC 1.1781 in the presence of formic acid (A), acetic acid (B), furfural (C), vanillin (D)

Three groups of fermentation inhibitors (weak acids, furan derivatives and phenolic compounds) would generate during pretreatment of lignocellulose [8]. In this study, representative inhibitors were added in media and the relative production was determined to investigate their effect. Fig. 1A and 1B shows that when the xanthan production reduced to $81.57 \%$ and $22.99 \%$ of control when formic acid and acetic acid concentration reached $0.6 \mathrm{~g} \mathrm{~L}^{-1}$ and $0.75 \mathrm{~g} \mathrm{~L}^{-1}$ respectively. The results in accordance with Esgalhado's report [12] that weak acid inhabitation on bacteria increased with the concentration at a certain external $\mathrm{pH}$. Some researchers consider that uncoupling effects lead to inhabitation [13]. Fig. 1C shows if furfural concentration was above $0.4 \mathrm{~g}$ $\mathrm{L}^{-1}$, xanthan production would decrease with the increase of furfural concentration. When the concentration was $0.8 \mathrm{~g} \mathrm{~L}^{-1}$ the relative level of production was reduced to $30.04 \%$. No previous researchers reported the inhibitory mechanism of the inhibitory of furfural on $X$. campestris, but some have found furfural can inhibit glycolytic enzymes of Saccharomyces cerevisiae [14]. The effect of phenolic compounds on xanthan production was studied using vanillin as a representative compound. Fig. 1D shows that vanillin strongly inhibited xanthan fermentation. The mechanism has not been elucidated because of a lack of accurate qualitative and quantitative analyses [8]. Fig. 1 indicates that $X$. campestris is sensitive to all the three groups of common inhibitors generated during steam explosion.
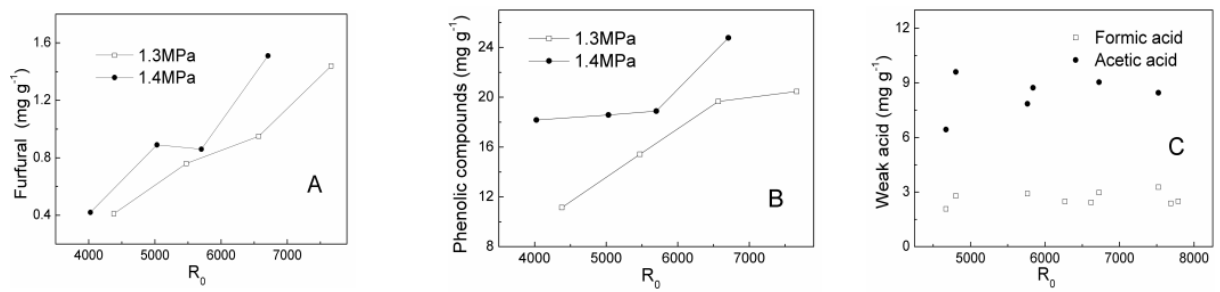

Figur 2 Correlation between steam explosion condition and inhibitors generation.

(A) furfural. (B) phenolic compounds. (C) acetic acid and formitic acid

$\mathrm{R}_{0}$, which is defined as $\mathrm{R}_{0}=\mathrm{t} \cdot \exp [(\mathrm{T}-100) / 14.75]$, is a parameter which reflects the intensity of steam explosion [15]. A $\mathrm{R}_{0}$ value may correspond to various combinations of steam pressure and maintain time. In this study, wheat straw was treated at several conditions. Fig. 2 shows that the correlation between weak acids, furfural and phenolic compounds content and the condition of steam explosion. Fig. $2 \mathrm{~A}$ and $2 \mathrm{~B}$ show that with the increase of $\mathrm{R}_{0}$, the content of furfural and phenolic compounds in SEWS increased accordingly. Fig. $2 \mathrm{C}$ shows that different from furfural and phenolic compounds, when $\mathrm{R}_{0}$ was between 4000 and 8000, the contents of the formic acid and acetic acid generated during steam explosion were rather stable. Formic acid and acetic acid content was between $6.5-9.5 \mathrm{mg} \mathrm{g}^{-1}$ and $2.0-3.0 \mathrm{mg} \mathrm{g}^{-1}$ respectively. Based on the data in Fig. 2, we can roughly calculate the inhibitor concentration in SEWS enzymatic hydrolysate. If SEWS is 
enzymatic hydrolyzed with a solid-liquid ratio of $1: 7$, furfural concentration is less than $0.21 \mathrm{~g} \mathrm{~L}^{-1}$, while acetic acid, and phenolic compounds are higher than 1.37 and $1.45 \mathrm{~g} \mathrm{~L}^{-1}$. It can be found that acetic acid and phenolic compounds concentration is enough to inhibit xanthan production. The speculation is in accordance with our experience. When the SEWS was hydrolyzed by cellulase and used to produce xanthan without any treatment, $X$. campestris could not growth and no xanthan was produced. The data in Fig. 1 and 2 suggest that detoxification is necessary for xanthan production using SEWS hydrolysate as carbon source. If we compare the trend lines of furfural, and phenolic compounds content at different steam pressure (Fig. $2 \mathrm{~A}$ and $2 \mathrm{~B}$ ), it is found that at a certain $\mathrm{R}_{0}$ value, more furfural and phenolic compounds were generated with the combination of high pressure and low maintain time. This suggests that furfural, and phenolic compounds can be reduced by optimizing the explosion condition.

Table 1 Effect of flocculation and air-drying

\begin{tabular}{ccccc}
\hline Inhibitor & $\begin{array}{c}\text { Carbohydrate } \\
\left(\mathrm{mg} \mathrm{g}^{-1}\right)\end{array}$ & $\begin{array}{c}\text { Formic acid } \\
\left(\mathrm{mg} \mathrm{g}^{-1}\right)\end{array}$ & $\begin{array}{c}\text { Furfural } \\
\left(\mathrm{mg} \mathrm{g}^{-1}\right)\end{array}$ & $\begin{array}{c}\text { Phenolic compounds } \\
\left(\mathrm{mg} \mathrm{g}^{-1}\right)\end{array}$ \\
\hline Untreated & 121.50 & 2.21 & 0.73 & 9.24 \\
Treat $1^{\mathrm{a}}$ & $114.56\left(6^{\mathrm{c}}\right)$ & $1.96(12)$ & $0.63(14)$ & $6.48(30)$ \\
Treat $2^{\mathrm{b}}$ & $117.50(3)$ & $1.96(12)$ & $0.64(12)$ & $6.90(25)$ \\
Air-drying & - & 0.48 & 0.04 & - \\
\hline Note: a. Treat1: & Adjusting the extraction to $\mathrm{pH} 10$ using CaO, and then neutralize it using $\mathrm{H}_{3} \mathrm{PO}_{4}$. \\
b. Treat $2:$ Adjusting the extraction to $\mathrm{pH} \mathrm{4} \mathrm{using} \mathrm{H}_{3} \mathrm{PO}_{4}$ and then neutralize it using CaO. C. Values in \\
parentheses represent percent removal as compared to untreated hydrolysate.
\end{tabular}

There are a lot of reports on inhibitors removal, for example rotary evaporation to remove volatile component, enzyme treatment to remove phenolic compounds and adsorption. Most of these methods were too complex or expensive, and simple and economical methods are required to enhance the fermentabiliy of lignocellulosic hydrolysate. In this study, we tried calcium phosphate flocculation which is used as a simple decolorization technology in sugar industry. Two procedures of forming precipitation were tried to treat SEWS extraction. The first was to adjust the extraction to $\mathrm{pH} 10$ with $\mathrm{CaO}$, and then adjusted to neutrality with $\mathrm{H}_{3} \mathrm{PO}_{4}$, while the second was adjusting the extraction to $\mathrm{pH} 4$ with $\mathrm{H}_{3} \mathrm{PO}_{4}$, and then to neutrality with $\mathrm{CaO}$. Table 1 shows the effect of the two procedures. With the first procedures, we removed $12 \%$ of formic acid, $14 \%$ of furfural and $30 \%$ of phenolic compounds respectively while with the second procedures, the removal rats were $12 \%$, $12 \%$, and $25 \%$, respectively (Table 1). The inhibitors can be removed is because the flocculated sediment has high specific surface area. Inhibitors could be absorbed onto the surface of small precipitate particles. Table 1 suggests that flocculation is effective to remove phenolic compounds, and adjusting hydrolysate to alkalescence and then neutralizing it by phosphoric acid is more effective than the contrary procedure. Table 1 also shows that in air-dried SEWS, weak acids and furfural derivatives were significantly less than those in fresh SEWS. The results suggested that during air-drying, most of weak acids and furan derivatives volatilized together with water vapor. Hence, air-drying was effective to remove the two groups of inhibitors. On the other hand, SEWS could be kept from going moldy and was convenient to be transported and stored if SEWS was air-dried, so the operation would not bring about additional burden to xanthan production with lignocellulosic hydrolysate.

Detoxified enzymatic hydrolysate of SEWS, which was exploded at $1.3 \mathrm{MPa}$ for $10 \mathrm{~min}$, was used as the carbon source to check the feasibility of xanthan production. Time course of fermentation and the structure characteristic (pyruvate content and acetate content) of xanthan derived from the hydrolysate were investigated. Fig. 3 shows that the original concentrations of glucose and xylose were 20.4 and $11.6 \mathrm{~g} \mathrm{~L}^{-1}$; maximum level of biomass was reached at $40 \mathrm{~h}$; the 
maximum levels of xanthan were at about $60 \mathrm{~h}$ when $15.9 \mathrm{~g} \mathrm{~L}^{-1}$ glucose and $5.9 \mathrm{~g} \mathrm{~L}^{-1}$ xylose were consumed. Obviously, the production of xanthan was slower than that cultured in glucose medium. It might be because of existence of residual inhibitors. The concentration of xanthan in the broth attained $20.7 \mathrm{~g} \mathrm{~L}^{-1}$ and the yield was $0.62 \mathrm{~g}$ xanthan per $\mathrm{g}$ sugar (glucose and xylose). Fig. 3 also showed that both xylose and glucose could be utilized by $X$. campestris, but the rate of xylose consumption was slower than that of glucose. This is in accordance with our previous report of xanthan fermentation using glucose and xylose mixture [19].

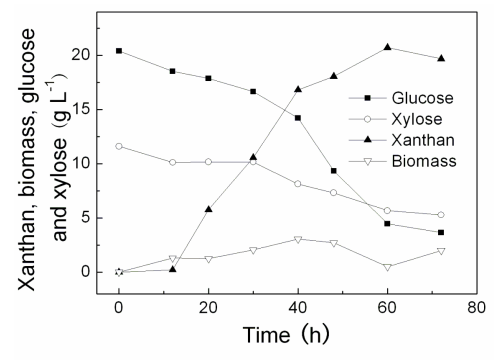

Figur 3 Time course of xanthan fermentation with enzymatic hydrolysate of steam-exploded wheat straw

Acetate content and pyruvate content of xanthan determined the rheological properties and applications of xanthan solution. Table 2 shows that the pyruvate content and acetate content of xanthan derived from hydrolysate were $3.76 \%$ and $8.46 \%$ respectively, while those derived from glucose media were $2.55 \%$ and $2.43 \%$. In our previous research [16], it was found that the contents of the two side chain groups of xanthan produced with glucose/xylose mixture were higher than those produced with glucose media, especially the acetate content, which was higher than that of previous reports. Hence the xylose might be an important reason of the side chain content difference.

Table 2 Comparison of the characteristics of xanthan derived from hydrolysate of steam-exploded straw and glucose

\begin{tabular}{ccc}
\hline & Xanthan derived from hydrolysate of SEWS & Xanthan derived from glucose \\
\hline Pyruvate content $(\%)$ & 3.76 & 2.43 \\
Acetate content $(\%)$ & 8.46 & 2.55 \\
\hline
\end{tabular}

\section{Conclusion}

$X$. campestris is sensitive to some compounds generated during the pretreatment on lignocellulose, including weak acid, furan derivatives and phenolic compounds. However, the fermentability of SEWS hydrolysate can be enhanced by the combine method. Flocculation is effective to remove phenolic compounds, while air-drying can be used to remove weak acids and furan derivatives. On the other hand, lower furan derivatives and phenolic compounds would be generated if the combination of low pressure and long maintain time is used in SEWS preparation. Using detoxificated hydrolysate, the xanthan production attained $20.7 \mathrm{~g} \mathrm{~L}^{-1}$ and the yield was $0.62 \mathrm{~g}$ xanthan per g sugar (glucose and xylose).

\section{Acknowledgments}

This work was supported by the University-Institute Cooperation Funds from UCAS (No. Y552017Y00) and the Start-up Research Funds for Young Teachers from UCAS (No. Y55103GY00) 


\section{References}

[1] A. S. Deshmukh, T. M. Aminabhavi, In: Polysaccharides: Bioactivity and Biotechnology, edtied by K. G. Ramawat and J. M. Mérillon (Eds.). Springer International Publishing (2015), pp1933-1967.

[2] K. Born, V. Langendorff and P. Boulenguer, in: Biotechnology of biopolymer Vol. 1, edtied by A. Steinbuchel, and Y. Doi, Eds. Weinheim: Wiley-VCH Verlag (2005).

[3] R. Ben Salah, K. Chaari, S. Besbes, N. Ktari, C. Blecker, C. Deroanne and H. Attiaa, Optimisation of xanthan gum production by palm date (Phoenix dactylifera L.) juice by-products using response surface methodology, Food Chem. 121 (2010), 627-633.

[4] H. Z. Chen and W. H. Qiu, Key technologies for bioethanol production from lignocellulose, Biotechnol. Adv. 28 (2010), 556-562.

[5] M. H. Yang, W. L. Li, B. B. Liu, Q. Li and J. M. Xing, High-concentration sugars production from corn stover based on combined pretreatments and fed-batch process, Bioresour. Technol. 101 (2010), 4884-4888.

[6] A. Rudolf, M. Alkasrawi, G. Zacchi and G. Liden, A comparison between batch and fed-batch simultaneous saccharification and fermentation of steam pretreated spruce, Enzyme Microb. Technol. 37 (2005), 195-204.

[7] P. Vaithanomsat, S. Chuichulcherm and W. Apiwatanapiwat, Bioethanol production from enzymatically saccharified sunflower stalks using steam explosion as pretreatment, World Acad. Sci. Eng. Technol. 49 (2009), 141-143.

[8] E. Palmqvist and B. Hahn-Hagerdal, Fermentation of lignocellulosic hydrolysates. II: inhibitors and mechanisms of inhibition, Bioresour. Technol. 74 (2000), 25-33.

[9] D. M. Li and H. Z. Chen, Biological hydrogen production from steam-exploded straw by simultaneous saccharification and fermentation, Int. J. Hydrogen Energy 32 (2007), 1742-1748

[10] American Public Health Association, Standard Methods for the Examination of Water and Wastewater, 16 ed. Washington, D.C. 1985.

[11] N. W. H. Cheetham and A. Punruckvong, An HPLC method for the determination of acetyl and pyruvyl groups in polysaccharides, in: Carbohydr. Polym. 5 (1985), 399-406.

[12] M. E. Esgalhado, J. C. Roseiro and M. T. Amaral-Collaço, Kinetics of acid toxicity in cultures of Xanthomonas campestris, Food Microbiol. 13 (1996), 441-446.

[13] M. E. Esgalhado, A. T. Caldeira, J. C. Roseiro and A. N. Emery, Sublethal acid stress and uncoupling effects on cell growth and product formation in Xanthomonas campestris cultures, Biochem. Eng. J. 12 (2002), 181-192.

[14] N. Banerjee, R. Bhatnagar and L. Viswanathan, Inhibition of glycolysis by furfural in Saccharomyces cerevisiae, European J. Appl. Microbiol Biotechnol. 11 (1981), 226-228.

[15] M. Ropars, R. Marchal, J. Pourqui and J. P. Vandecasteele, Large-scale enzymatic hydrolysis of agricultural lignocellulosic biomass. Part 1: Pretreatment procedures, Bioresour. Technol. 42 (1992), 197-204.

[16] Z. G. Zhang, and H. Z. Chen, Fermentation performance and structure characteristics of xanthan produced by xanthomonas campestris with a glucose/xylose mixture, Appl. Biochem. Biotechnol. Vol. 160 (2010), 1653-1663 